\title{
Ana Hofman (ed.) \\ SCIENCE (WITHOUT) YOUTH: Gendering Early Academic Careers in Slovenia
}

\author{
Ljubljana, Založba ZRC, 2017
}

How is it possible to foster gender equality in academia if the academic field is gradually marked by precarity, particularly in the early stages of academic careers? How do early career scholars deal with the challenges of their professional environments and what are the potential strategies of structural change that can contribute to the improvement of equal opportunities in academia? These are the questions that Science (without) Youth: Gendering Early Careers in Slovenia [Znanost (brez) mladih: Zgodnje stopnje znanstvene kariere skozi perspektivo spola] raises and strives to discuss in its introduction and the seven chapters that follow. The book is a result of the GARCIA project that targets combating gender inequalities in academia by taking an innovative approach - focusing on researchers in non-tenured, temporary positions. ${ }^{1}$

The book is based on extensive analyses of various types of materials - formal acts and policies, quantitative and qualitative data (40 semi-structured interviews, 20 in Science, technology, engineering, and mathematics - STEM and 20 in Social sciences and humanities - SSH selected target institutions). ${ }^{2}$ Such an approach enables the authors to provide insight into the complexities of the gender regimes in Slovenian academia, by putting statistics and structural level analysis side by side with personal accounts. The introduction presents the readers with the general conceptual orientation of the book, situating the approach to the issue of gender asymmetries within the current processes of the neoliberalisation of academia. ${ }^{3}$ After giving an overview of the relevant literature on the topic and an extended explanation of the methodology, the introduction further discusses the

1 "Gendering the Academy and Research: Combating Career Instability and Asymmetries"; for more information about the project, cf. http://garciaproject.eu/.

2 This encompasses three target sub-groups: postdocs, newly tenured staff, and the so called movers/leavers. The latter were defined as people who (1) had moved from the higher education/research institution to continue their research careers (in the same or a different country) at public or private universities or research centres, or who (2) had left the higher education/research institution to embark on careers unrelated to research.

3 The authors are completely aware of the necessity to differentiate between different academic institutions and national higher education and research systems when discussing the issue of the neoliberalisation of academia. 
structural conditions that crucially affect gender-related imbalances: changing funding patterns, policy of new managerialism, casualisation of academic work, working patterns and unpaid labour, and the Leaky Pipeline phenomenon. ${ }^{4}$ The introduction is followed by two chapters that analyse formal acts, policies and quantitative research: in the opening chapter, Sanja Cukut Krilić critically reflects on the current approaches to the issue of gender equality that rarely take into account social norms and expectations; she argues for the necessary inclusion of the intersectional approach to the various layers of social stratification in the future analysis of this topic. In the second chapter, Majda Černič Istenič presents the degree to which gender-sensitive statistics in Slovenia follow the global international trends of uncovering the leaving and leakage of female $\mathrm{PhD}$ holders from academia. This chapter problematises the gap, reflected in the lack of key information on leaving the academic sphere and the related unemployment rate, which could shed light on the overall trends as well as the magnitude of the loss of young people in contemporary academia. The next four chapters take the qualitative approach and discuss three main topics: work-life balance policies and practices, construction of excellence (in recruitment and promotion), and mentoring practices. Tanja Petrović focuses on the dynamics of the professional versus the other aspects of the academic's life, showing that women (and men) in the early stages of an academic career may not be facing the same structural and normative opportunities and constraints in institutional and disciplinary contexts. In the chapter on the construction of academic excellence in Slovenia, Jasna Fakin Bajec and Polona Sitar reveal gendered sub-texts in the experiences of the recruitment procedures of their interlocutors. They show how 'excellence' is not a gender-neutral objective notion, but rather a socially constructed, constantly changing process, one that continually reproduces the underlying gender assumptions and the subordinated or excluded position of women. The following chapter by Duška Knežević Hočevar reflects on the practices of mentoring and the way mentorship is experienced in the SSH and STEM fields. After she gives an historical overview of the programme for Young Researchers (1985) and discusses the lack of official mentoring programmes for early career researchers, the author argues that it is necessary to approach the issue of mentorship within the context of academic neoliberalism and the current construction of scientific excellence criteria. Based on an analysis of the dominant discourses and ongoing public debates, as well as the comparative analysis conducted by the GARCIA project, the last chapter on academic (im)mobility in the context of Slovenian academia, written by Jovana Mihajlović Trbovc, offers reflections on the structural factors that determine the advantages and disadvantages of mobility for academics at the early stages of their careers. The chapter particularly examines the construct of a 'national science' and the structural self-reproduction of the academic community (so called academic inbreeding) in Slovenia. The concluding contribution by Oto Luthar engages with some concrete circumstances and conditions of gender asymmetries in Slovenian academia and makes suggestions for dealing with them. The contribution tries to pay attention to the dynamics between politicised 'performance',

4 A metaphor that refers to dropping out of the scientific profession and manifests itself in the poor representation of women at all levels of academic profession. 
which is not directed at solving accumulated problems, and substantial action in the interest of the academic community.

Science (without) youth shows that a focus on early career researchers does not just afford a more nuanced view of gender inequality but provides insight into the growing inequality among academics in Slovenia and Europe as well. The book strives to take an intersectional approach as the authors have tried to look at how gender roles intersect with ethnicity, class, religion, age, etc. Moreover, the book strives to express gender pluralism and challenge cisnormativity and androcentrism in language, being the first scholarly book in Slovenia that implements the usage of the underscore, for which it has already gained attention among academics in Slovenia. Book is fully available in electronic form at: https://ikss.zrc-sazu.si/sites/default/files/attachments/znanost_brez_mladih_web.pdf. 